En la casa (tono familiar):

Este muchacho siempre pensando y escribiendo disparates.

Sin embargo sus familiares están equivocados, pues Jiménez no piensa ni tampoco escribe disparates, sino tonterías. El disparate-se sabe-es siempre divertido, sugeridor de la sonrisa, del amable regocijo, mien tras que la tontería es triste y produce compasión, aún en los individuos más anticristianos. Y después de la lectura de Gleba, hemos tenido que compadecer a su autor, muy a pesar nuestro, por una imperiosa necesidad justificativa.-Arturo Troncoso.

\section{ESTUDIOS SEXUALES}

El SEXO EN LA CIVILIZACIÓN, por varios autores, reunido por $V . F$. Carlverton y S. D. Schmalhausen.

Alguien, creo que un autor francés, ha dicho que el mundo moderno vive en plena edad media sexual. Ha querido decir con esto, seguramente, que el mundo lucha en estos momentos por llegar a una fijación exacta del problema sexual, de la conducta sexual, de la definición sexual. La biología sexual constituye hoy día uno de los más apasionantes temas científicos y ha dado margen a creaciones maravillosas de la inteligencia humana. Fuera de la biología el interés no es menor. El sexo abarca casi todos los campos de la actividad humana y sus relaciones son infinitas; todo cabe en ellas, desde las creaciones artísticas hasta los ritos religiosos. Poco a poco se descubren nuevas vetas y se fijan nuevas características, características morales, intelectuales, fisiológicas, que identifican al individuo dentro de tal o cual rama sexual.

Este libro contiene treinta ensayos de autores diversos, en su mayoría de nacionalidad americana, y está dedicado ea esas mujeres que tomaron parte en la lucha por la emancipación del sexo y por una civilización mejor '. Esas mujeres son: Mary Wollstonecraft, Jorge Sand, Ellen Key, Oliva Schreiner, Lilli Braun, Isadora Duncan, Aletia Jacobs, Alejandra Kollontay, María Stopes y Dora Russell. Hay entre ellas doctoras como María Stopes, bailarinas, como Isadora Duncan, y educacionistas, como Ellen Key; escritoras, como Jorge Sand, y revolucionarias comunistas, como Alejandra Kollontay, mujẹres todas que han sobresalido, con sus obras y con sus vidas, de la masa femenina y que han contribuido a crear para la mujer una norma espiritual nueva.

Principia el libro con un ensayo de Roberto Briffault sobre El sexo cn la religión y termina con otro de Roberto Morss Lovett, sobre El sexo y la novela. Arturo Davison Ficke escribe un interesante estudio sobre la poesía sexual, tema novísimo, con citas de autores norteamericanos e ingleses, que demuestran el lento proceso de desarrollo de la poesía amorosa, desarrollo que está directamente influenciada por las ideas sexuales reinantes en cada época literaria.

El total del libro está dividido en 
seis partes: El sexo a través de los siglos, El papel del sexo en la conducta, El sexo y la psico-sociología. El sexo y la psico-análisis, Los aspectos clínicos del sexo, y El sexo en la poesía y en la novela.

Nada ha escapado a los compiladores de estos ensayos, los escritores V. F. Calverton y S. D. Schmalhausen, que aparecen en el libro con dos ensayos, el primero sobre $\mathrm{El}$ sexo $y$ la lucha social y el segundo con $L a$ revolución sexual. Waldo Frank es- cribe sobre La censura sexual y la democracia. Ocho mujeres contribuyen también a dar amplitud a este libro, voluminoso y completo, lleno de apasionantes estudios, cuyo análisis nos llevaría demasiado lejos. Basten las líneas anteriores para destacar la importancia excepcional de esta recopilación, que agrupa tantos csfuerzos considerables en el estudio de la faz sexual de la vida contemporánea. $-M$. $R$. 